\title{
Students' Analogical Reasoning in Solving Trigonometric Problems in Terms of Cognitive Style: A Case Study
}

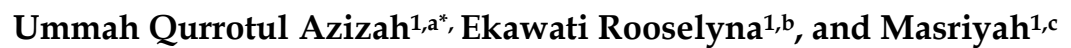 \\ ${ }^{1}$ Department of Mathematics Education, Postgraduate, State of University Surabaya, Surabaya, 60213, Indonesia \\ Azizah.17070785018@mhs.unesa.ac.id \\ *Corresponding Author : Azizah.17070785018@mhs.unesa.ac.id
}

\begin{abstract}
This article discusses the analogical reasoning of students' types in solving trigonometric problems based on cognitive styles. This research was conducted at MAN I Probolinggo, eighteen students was asked to complete cognitive style tests and math ability tests. It was found that students' answers can be grouped into two types of cognitive styles, namely systematic and intuitive. From each group, one student was taken to be interviewed with the aim of getting a more detailed explanation of each type of analogical reasoning. The results show that the two types can be explained as follows, first, the type of systematic cognitive style, students can understand the problem given, mention in detail all the information that is known and asked, use all known information about the problem, read and understand the problem, map the structure relational problems, applying a structured way to solve problems that have been planned in advance. In the intuitive cognitive style type, students can understand the problem only by reading the problem once, mention some information that is known about the problem, use the information that is known in the problem, read and understand the problem, apply problem-solving methods. pre-planned but unstructured. Therefore, teachers must encourage and enable students to use analogical reasoning optimally in learning mathematics.
\end{abstract}

Keywords: Analogical Reasoning; Problem Solving; Cognitive Style; Systematic; Intuitive

\section{Introduction}

Mathematics is not just completing a series of exercises or mimicking a teacher-taught process, but doing math means coming up with strategies used to solve problems, implementing them, seeing if they lead to the desired solution, and checking back to see if the answers presented make sense(Van de Walle et al., 2013). For this reason, all students must have the same opportunity and support to learn mathematics with a deep understanding (Graham, \& Fennell, 2001). Learning mathematics is expected to produce someone who is creative, critical, competent, and able to solve daily problems with a good mindset. NCTM(in. Hasbi et al., 2019)"establishes five standards in mathematics that students must possess, namely problem-solving skills, communication skills, connections, reasoning and proof, and representation skills". The reasoning is an important element in learning mathematics because, in addition to using reasoning to solve problems, reasoning is also the goal of learning mathematics(Hill, \& Ball, 2004). Mathematics learning must be able to develop students' problem solving and reasoning abilities. NCTM (2000) "One of the benefits of reasoning in learning mathematics is to help students improve their ability from simply remembering facts, rules, and procedures to understanding skills". Mathematical material and mathematical reasoning are two things that cannot be separated, meaning that mathematics material is understood through reasoning, and reasoning is understood and trained through mathematics learning (Depdiknas, 2006). Reasoning is a very important ability in learning mathematics because besides being used to solve problems, the reasoning is also the goal of learning mathematics. This is supported by the statementLehrer, \& Schauble, (2000); Bergqvist, (2007); Jeannotte, \& Kieran, (2017) state that reasoning is very important in mathematics, both in learning mathematics and in the use of mathematics.

According to the standard process NCTM (2000) several abilities classified as mathematical reasoning include (a) drawing logical conclusions, (b) providing an explanation of models, facts, properties, relationships, or patterns, (c) estimating answers and process solutions, (d) ) use relationship patterns to analyze situations, or make analogies, generalize, and construct conjectures, (e) propose counterexamples, (f) follow inference rules, check the validity of arguments, prove, and construct valid arguments, and (g)) construct a direct proof, circumstantial proof, and proof by mathematical induction. Based on this statement, 
making an analogy is an indicator of student reasoning. Mofidi et al. (2012) argued that analogy is a way of focusing on equations that are interrelated and independent of several connected objects. Analogy is the ability to understand and operate on the basis of the similarity of the structure of an object whose surface features are not always the same, is also considered an important part of human capacity to adapt to new contexts (Richland et al., 2004; Richland, \& Simms, 2015; Richland, \& Begolli, 2016). Meanwhile, according to Kariadinata (2012: 14), analogy is comparing two different things based on their similarities. Apart from looking for similarities between two different things, analogy also draws conclusions on the basis of these equations. Based on some of the opinions above, analogy is a way of looking at two different things by paying attention to the similarities in nature and the relationship between the two.

Learning mathematics involves two aspects of reasoning, namely deductive reasoning and inductive reasoning. Isoda \& Katagiri (2012) stated that: "Analogical reasoning is a method of thinking that is very important for building perspectives and finding solutions". When students carry out the problem-solving process, analogical reasoning is of course already in it because analogical reasoning is needed to make it easier for students to solve these problems. Meanwhile, Gentner\& Smith (2013) "analogical reasoning is reasoning that uses special cases, where what is known in one case can be used to predict information about other cases". A process to derive conclusions using the general nature of the structure of the relationship between a known problem (basic form or source) and a new problem (Bassok, 2001; Holyoak et al., 2001). In line with English (2004) states that analogical reasoning consists of reasoning with classical analogies, reasoning with problem analogies, and reasoning with pedagogical analogies. Thus, analogical reasoning is the process of drawing conclusions using the similarity of properties and structure of the relationship from a known problem source to apply to the target problem.

Analogical reasoning has a very important role in learning mathematics. Mofidi et al. (2012) revealed that one of the effective ways teachers can teach mathematical concepts is by using problems that involve analogical reasoning. Analogical reasoning ability in mathematics learning can be used to teach a mathematical concept to students by describing an abstract concept into concrete so that students are able to understand mathematical concepts. According to Piaget, students' intellectual development has reached the final stage (formal operation) at the age of 12, at that age at the junior high school level to be precise (Huitt, \& Hummel, 2003; Lefa, 2014; Bormanaki, \& Khoshhal, 2017). Furthermore, based on research conducted by Hendrawata (2018) shows that the analogical reasoning of junior high school students is still low so that students' analogical skills in solving math problems need to be improved. To better see the emergence of analogical reasoning, researchers will conduct research at the Madrasah Aliyah (MA) level. According to Shadiq (2013) "In trigonometric material, a student can draw conclusions $\cos (300+600)=\cos 300+\cos 600$ because in the source problem $3(2+5)=(3 \times 2)+(3 \times 5)$. Of course this is not the same because $\cos (300+$ $600)=\cos 900=0$ while $\cos (300+600)=\frac{1}{2} \sqrt{3}+\frac{1}{2}$. However, for $3(2+5)=3 \times 7=21$, while for $(3 \times 2)+(3 \times$ $5)=6+15=21$. In general, $3(x+y)=3 x+3 y$ while for $\cos (A+B)=\cos A+\cos B$, so the analogy of the distributive property of multiplication to the addition of real numbers does not apply to the concept of trigonometry. To train students to use analogical reasoning, the teacher needs to guide students to correct these errors by asking questions about meaning $3(\mathrm{a}+\mathrm{b})$ and the meaning of $\cos (\mathrm{A}+\mathrm{B})$ so that students can decide for themselves whether the analogy can be used ". The relationship between the knowledge that students already know and learning new knowledge will make it easier for students to learn mathematics. Therefore, it is necessary to carry out further research related to students' analogical reasoning in trigonometric material.

Each student has different characteristics in thinking and solving problems. Students' thinking processes are influenced by the speed at which these students receive and process information(Vahrum\& Rahaju, 2016). If it is associated with the definition of reasoning, namely thinking activities to draw conclusions correctly based on several statements whose truth has been proven previously (Sadiq et al, 2007), students' reasoning is influenced by cognitive styles. Cognitive style is one of the distinguishing aspects which refers to the characteristics of a person is receiving, processing, storing, thinking, and using the information in response to a task or various types of environmental situations (Alamolhodaei, 2002). Understanding cognitive style according toSternberg \& Williams (2009) "Cognitive style is the basis that differentiates between individuals when they interact with elements of a situation and is also an important approach to understanding and how someone thinks". Meanwhile, according to (Altun \& Cakan, 2006)"Cognitive style has a broader meaning, which refers to the way people obtain information and views their surroundings as stimuli and interacts with it." Cognitive style is a stable personal attribute that reflects the consistent way in which individuals organize and process information, and ultimately make decisions and actions (Sagiv et al., 2010).

Systematic and intuitive cognitive style is one dimension of cognitive style related to mathematics learning which is also the focus of this research. Individuals with a systematic (rational) style tend to apply 
rule-based thinking (Smith \& DeCoster, 2000). They analyze situations and logically evaluate alternatives in an attempt to find the underlying rules. These rules help them organize the world into systematic patterns that they can rely on when choosing how to act (Scott \& Bruce, 1995). Individuals with an intuitive style tend to apply associative thinking (Smith \& DeCoster, 2000), also called experiential thinking (Norris \& Epstein, 2011). They have a holistic and global perception (Scott \& Bruce, 1995)and are often unaware of their thinking patterns. They integrate associations and rely on intuition, taking into account not only facts but also feelings and context (Sternberg, 1998). An artist, for example, tends to have an intuitive style. In the workplace and in other contexts, artists tend to analyze situations in complex and holistic ways, connecting pieces of information associatively. Based on the description above, it is very important to conduct research to reveal how students' analogical reasoning in solving trigonometric problems in terms of cognitive style. Therefore, this study aims to describe the analogical reasoning of MA students who have a systematic and intuitive cognitive style in solving trigonometric problems.

\section{Materials and Methods}

This study includes research with a qualitative approach. The data obtained in this study are written data and interview data in solving trigonometric problems which will then be analyzed and concluded. Selection of subjects begins with class selection by determining the group of students in MAN 1, Probolinggo City, namely class XI MIA 2 which consists of 18 students. Furthermore, the researcher gave two tests to all students, namely the Cognitive Style Test (TGK) and the Mathematical Ability Test (TKM), so that two subjects were selected, namely two students of MAN 1 Kota Probolinggo class XI 2020/2021, namely students who have a systematic and intuitive cognitive style. of the same gender and the same math abilities. The instruments used in this study included cognitive style tests (TGK), mathematics ability tests (TKM), analogical reasoning tests (TPA), and interview guides. Before being used, the four instruments were guided and validated by a psychology lecturer and two experts, namely two mathematics lecturers. The problem can be seen in Figure 1.

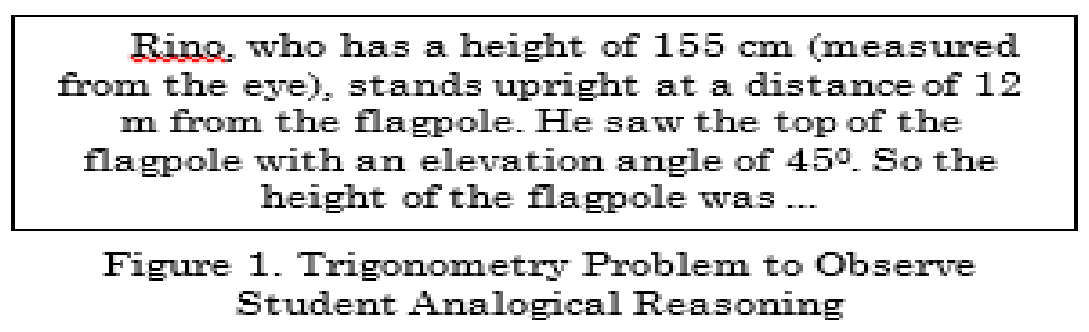

\subsection{Data Collection Technique}

Data collection in this study was carried out by means of tests and interviews. In this study, the tests used were the Cognitive Style Test (TGK), Mathematics Ability Test (TKM), and the Analog Reasoning Test (TPA). TGK is used to classify students based on a systematic and intuitive cognitive style. TKM is used to determine the mathematical abilities of each subject which have been grouped into 2 groups, namely systematic cognitive style and intuitive cognitive style. After that, the subjects who have been determined to work on TPA 1 get data about students 'analogical reasoning in solving trigonometric problems, TPA 2 aims to triangulate MA students' analogical reasoning data in solving trigonometric problems.Interviews are conducted after students have finished working on the TPA so that no information is missed and the validity of the data obtained is guaranteed. This study uses direct and semi-structured interviews. Interviews in this study were conducted after the research subjects completed the TPA. Interviews between researchers and subjects were recorded using audio-visual tools to obtain accurate data and no information was missed.

\subsection{Data Analysis Technique}

To ensure the validity of the data in this study, the first step needed is a research data checking technique. In qualitative research, data is obtained from various sources using various data collection techniques. Therefore, the authors used time triangulation to double-check the results of the TPA and interviews by giving tests at different times. Activities in data analysis are data condensation, data presentation, and verification/conclusion.

\section{Results and Discussions}

From the two groups with different types of answers, the first group involved a systematic cognitive style. The second group involves core cognitive styles. To find out more about students' analogical reasoning, here are the results of interviews with the two students, namely student 1 (S1) and student 2 (S2. 


\subsection{Analogical Reasoning in Problem Solving Process of (S1)}

$\mathrm{S} 1$ has written all the facts in the problem. This means that $\mathrm{S} 1$ understands what is given and what should be found in the problem. From the student sheet, it is known that $\mathrm{S} 1$ also writes, as shown in Figure 2.

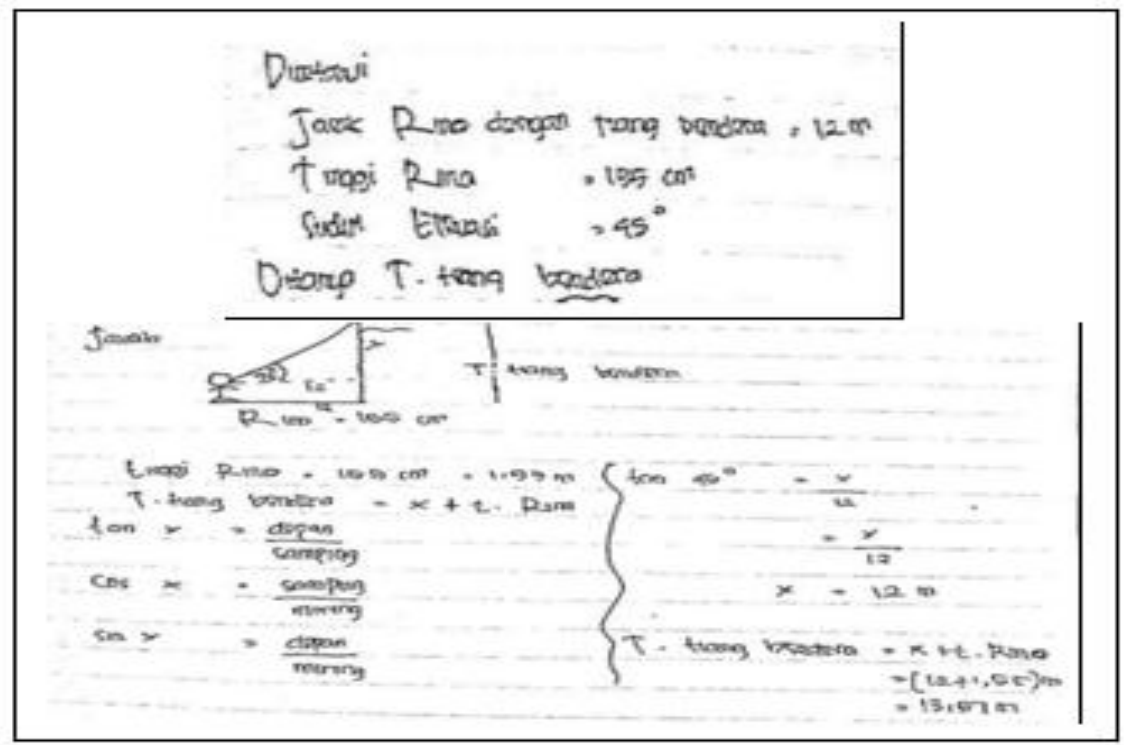

Figure 2. Conjecture by S1

The following is an interview with S1 regarding analogical reasoning in solving problems step encoding, inferring, maping, and applying.

\section{Encoding}

P: Okay, now from question number 1 first. What information do you get from this question?

$\mathrm{S}$ : The distance between Rino and the flagpole is $12 \mathrm{~m}$, the elevation angle is $45^{\circ}$ and Rino is $155 \mathrm{~cm}$ high.

P: Okay, after you write down what is known. Then you are told to find what the problem is?

S: Asked to find the height of the flagpole, Ma'am

Q: Have you read the previous question, how many times do you need to read it to understand this problem?

S: Maybe three ma'am.

P: Why three times? When reading how?

S: To make sure all known information is complete while thinking about how to solve it later.

Based on the presentation of S1 analogical reasoning data in solving problems, by that S1 mentions known information in the source of the problem and can show the sentence in the question, and can determine the information asked, mention the information in the question in the target problem and can show the sentence in the problem. and can determine the information asked for in the target problem.

\section{Inferring}

Q: OK, what are the next steps you took to solve the problem ?.

S: I drew it first, Ma'am, according to what you know there are pictures of people and a flagpole.

P: Then to do this problem which concept did you use ?.

S: After I saw the picture, I used tangent trigonometric ratios to find the height of the flagpole ma'am.

Based on the written results and the interview transcript above, that S1 uses the source of the problem information to answer questions by illustrating in the picture first and arranging ways to solve the source of the problem by looking for the relationships contained in the source of the problem.

\section{Mapping}

Q: How to find the height of the flagpole in that problem ?.

S: I was confused Ma'am if I immediately looked for the altitude. I drew this first, then after I saw the picture I couldn't immediately find the height of the flagpole, ma'am. So I have to know the value of $x$ first. 
S: Use the trigonometric ratio of the front and the sides of the right triangle Ma'am.

Q: Why did you use that method to solve the problem?

$\mathrm{S}$ : Since the $\mathrm{x}$ we want to find is the front side of the angle of $45^{\circ} \mathrm{Ma}$ 'am, besides that we also know the sides of the corner Ma'am.

Based on the data analysis, that S1 pays attention to problem-solving and uses the concept of problemsolving to solve the problem, namely the concept of tangent trigonometric comparison by looking at the relationship between the sides and angles of a right triangle to find unknown sides. at length and can explain the reasons for using the concept.

\section{Applying}

P: OK, how do I solve that problem ?.

S: You see Ma'am, at first I wrote down all the known information and asked about the problem. Then I picture ma'am. After I saw the picture I made, before finding the height of the pole I had to know the length $x$. Now to find $x I$ use the trigonometric ratio tangent bu because $x$ is the front side of the known angle.

$P$ : Then how high is the flagpole?.

S: After I get the $x$ value, I proceed to find the height of the flagpole by adding the $x$ value and the height of the rino. So the height of the flagpole is $13.55 \mathrm{~m} \mathrm{Ma}$ 'am.

Based on the presentation of analogical reasoning data from S1 in solving problems, it can be concluded that S1 solves problems appropriately using the appropriate comparison concept.

3.2 Analogical Reasoning in Problem Solving Process of (S2)

The following are the results of the Analogy Reasoning Test and excerpts of the interview transcript of the encoding, concluding, mapping, and implementing stages.

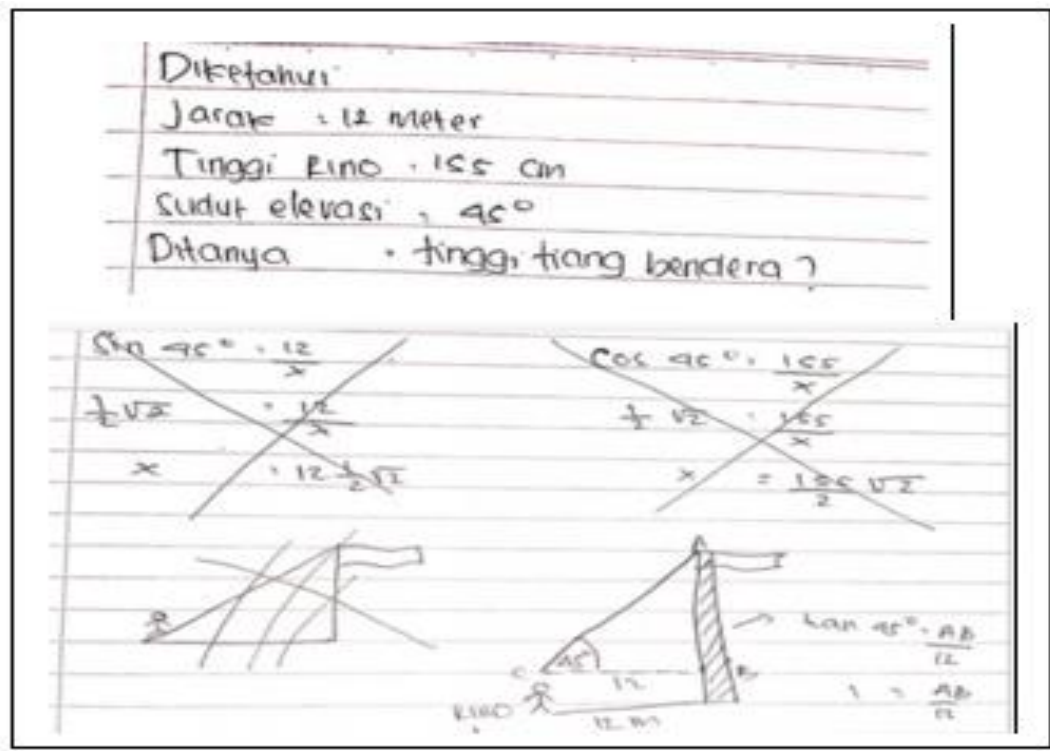

Figure 3. Conjecture by $\mathbf{S} 2$

\section{Encoding}

P: Okay, now from that question, what information do you get from that question?

S: Distance 12 meters, height $155 \mathrm{~cm}$ Rino and elevation angle $45^{\circ} \mathrm{Ma}$ am.

P: Then what are you looking for?

S: The height of the flagpole, Ma'am.

P: You have read the question earlier, about how many times you read it so you understand about this ??

S: Just once, Mom.

Based on the presentation of S2 analogical reasoning data in solving problems, that S2 mentions the information that is known in the problem and mentions the information that is known and can determine the information asked in the problem but is incomplete in stating the known information. 


\section{Inferring}

Q: What are the next steps you took to solve this problem?

S: I drew it first Ma'am according to what was known in the question.

P: Then to do this problem which concept did you use?

S: It seems offensive Ma'am.

Q: What is the reason you use tangents?

S: Um.... Yes, because the photo, Ma'am, what you are looking for is the front.

P: So how do you do this to solve this problem?

S: So at first I drew it, Ma'am. Then I was told to find BC. I use comparisons tangent trigonometry Ma'am.

Based on the written results and the interview transcript above, that S2 Uses all known information about the problem to answer the question by illustrating in the picture first and solving the source problem correctly using the concept of trigonometric comparisons on a right triangle by looking at the relationship between the sides and the angle in a right triangle but can't explain it.

Mapping

Q: How to find the flagpole height in this case?

S: I will look at the photo ma'am. After I gave the $A B C$ to the picture, then I used the trigonometric comparison Ma'am.

P: Then how do you find the height of the flagpole?

S: After obtaining the length of the tangent, then Rino height is added up.

Based on data analysis, it can be concluded that S2 pays attention to problem-solving and uses the concept of problem-solving to solve the problem, namely the concept of tangent trigonometric comparison by looking at the relationship between the sides and angles of a right triangle to find the unknown side length.

Applying

Q: How did you solve the problem?

S: I drew it, Ma'am .. Then I looked for the AB length first to find the height of the flagpole. I am finding the length $\mathrm{AB}$ using tangents.

P: How about after that?

S: After that, to find the height of Ma'am's flagpole, the rest was added to Rino's height.

$\mathrm{P}$ : It means that the flagpole is $13.55 \mathrm{~m}$ high, right?

S: Yes ma'am, that's the result.

Based on the presentation of analogical reasoning data from S1 in solving problems, it can be concluded that $\mathrm{S} 1$ solves problems appropriately using the appropriate comparison concept.

\subsection{MA students' Analogical Reasoning with Systematic Cognitive Style in Solving Trigonometric}

Problems

Based on the results of the study, it shows that students systematically solve a problem using similarity through previous knowledge that is similar to the problem to be solved. At the Encoding stage, students understand the problem systematically by reading the questions three times. Students systematically mention in detail all the information that is known and asked in the questions correctly without any information left behind. This is in accordance with the opinion of Martin (1998) which states that individuals with a systematic cognitive style tend to analyze and interpret problems carefully before starting the solving process to avoid repetition of problem-solving steps so that they appear to be very careful.

In the closing stage, the subject systematically uses all known information about the source of the problem to answer questions by illustrating in the picture first. Systematic subjects use all the information about the source of the problem that has been illustrated in the form of a picture to find related concepts, namely the relationship between the sides and angles in a right triangle and the trigonometric ratio of tangents. At this stage, the subject of systematics also writes in detail the trigonometric comparisons starting from tan, sin, and cos on the grounds that it is easier to find the length in question and is not wrong when working. This is in accordance with the opinion of Martin (1998) that students with a cognitive style analyze and interpret problems systematically and make careful plans before starting the completion process. Students can choose the right procedure to solve the problem by analyzing the relationship between the problems contained in the questions and the selected procedure. In addition, students in a systematic cognitive style appear to be very careful when selecting procedures and using related concepts and all 
known information in questions.

At this stage the subject systematically finds low-level (low-level) relationships between interrelated concepts to be used in solving the source problem. This is in accordance with English (2004) which states that at the stage of concluding the subject is systematically looking for lower-level relationships (lower order) contained in the problem. At the Mapping stage, the subject systematically looks for high-level relationships, namely the components in the source of the problem related to the problem-solving target component. This is in accordance with the opinion of English (2004) "the Mapping stage of the subject looks for high-level relationships (high order), namely building information on each problem". At the application stage, the subject systematically applies the source problem-solving method to solve the target problem that has been planned beforehand so that the subject systematically resolves the target problem using the source problemsolving structure. This is in accordance with the opinion of English, (2004) "students in solving target problems pay attention to the source of the problem and apply the problem source structure to the target problem".

\subsection{MA Students' Analogical Reasoning with Intuitive Cognitive Style in Solving Trigonometry} Problems

Based on the results of the study, it shows that the intuitive subject solves a problem using equations through prior knowledge which is similar to the problem to be solved. In the Encoding stage, the subject intuitively understands the problem by reading the questions only once. The intuitive subject can name some information that is known in the problem and not know other information which is known information from the source of the problem. The intuitive subject also does not completely write down known information about the target problem on the answer sheet. In the interview, the intuitive subject also mentioned information that was not fully known about the target problem even though he finally realized and completed the information. This is in accordance with the opinion of Martin (1998) who revealed that they tend not to take problem-solving steps sequentially, often jumping from one stage of analysis or information gathering to another and back again.

At the conclusion stage, the intuitive subject uses the information known in the problem to be illustrated in advance in the picture to answer the question. Furthermore, the intuitive subject uses all the information about the source of the problem that has been illustrated in the form of an image to find related concepts. In formulating steps to solve the source of the problem, the intuitive subject appears to be conducting an experiment, seen from the answer sheet and revealed from the results of the interviews that have been conducted. But in the end, the intuitive subject was able to determine the concept of tangent trigonometric comparison to solve the source problem. This is in accordance with the opinion of Jena (2014) which states that students who have an intuitive cognitive style have a tendency to solve problems through unplanned analytical stages, based on their experiences, and try to explore various alternatives that can produce solutions quickly.

At the Mapping stage, the intuitive subject looks for high-level relationships, that is, the components in the source problem are related to the target problem-solving component. This is in accordance with the opinion of English (2004) "at the Mapping stage the subject looks for high-level relationships, namely building information about the problem".

At the application stage, the intuitive subject applies a pre-planned problem-solving method so that the subject systematically solves the target problem using the source problem-solving structure. This is in accordance with the opinion (English, 2004) which states that students in solving target problems pay attention to the source of the problem and apply the problem source structure to the problem target. Although in planning that is done, intuitive subjects tend to jump up and down seen from the results of their work and from the results of interviews with intuitive subjects. This is in accordance with the opinion of Kent (1985) "individuals with an intuitive cognitive style prefer trial and error, rely on cues, and easily jump from one solution to another".

\section{Conclusion}

This study describes students' analogical reasoning in solving trigonometric problems based on a systematic and intuitive cognitive style. The results showed that at the Encoding stage, students understood the understanding of the questions given by reading the questions three times. Students systematically mention in detail all the information that is known and asked about the source of the problem and the target of the 
problem correctly without any information being left behind. In the Inferring stage, students systematically use all known information on the source of the problem to answer questions by illustrating in the picture first. The subject systematically uses all the information about the source of the problem which has been illustrated in the form of an image to find related concepts. The subject systematically concludes that the concepts used in problem-solving can be used to target problem-solving. This shows that the systematic subject has mapped the relational structure from the source of the problem to the target problem by identifying the similarity of these relational structures.

In the Encoding stage, the subject intuitively understands the problem by reading the questions only once. The intuitive subject can enumerate some known information in the problem and other unknown information which is unknown information at the source of the problem. At the basic conclusion stage, it intuitively finds low-level relationships between interrelated concepts for use in solving the source problem. Whereas at the mapping stage, the intuitive subject looks for high-level relationships, namely the components in the source of the problem associated with the target component of problem-solving. At the application stage, the subject applies the source problem-solving method to solve the target problem that has been planned beforehand so that the subject systematically resolves the target problem using the source problem-solving structure. However, the intuitive subject cannot explain the reasons for using the method to solve problems.

\section{References}

Amir-Mofidi, S., Amiripour, P., \& Bijan-Zadeh, M. H. (2012). Instruction of mathematical concepts through analogical reasoning skills. Indian Journal of Science and Technology, 5(6), 2916-2922. https://doi.org/10.17485/ijst/2012/v5i6.12

Almolhodaei, H. (2002). Students' Cognitive Style and Mathematical Word Problem Solving. Journal of the Korea Society of Mathematical Education Series D Research in Mathematical Education, 6(2), 171-182. https:// www.koreascience.or.kr/article/JAKO200211921431195.page

Altun, A., \& Cakan, M. (2006). International Forum of Educational Technology \& Society Undergraduate Students ' Academic Achievement, Field Dependent / Independent Cognitive Styles and Attitude toward Computers Published by : International Forum of Educational Technology \& Society Lin, 9(1).

Bassok, M. (2001). Semantic alignments in mathematical word problems. The analogical mind: Perspectives from cognitive science, 401-433. https:// psycnet.apa.org/record/2001-00520-011

Bergqvist, E. (2007). Types of reasoning required in university exams in mathematics. The Journal of Mathematical Behavior, 26(4), 348-370. https://doi.org/10.1016/i.jmathb.2007.11.001

Bormanaki, H. B., \& Khoshhal, Y. (2017). The role of equilibration in Piaget's theory of cognitive development and its implication for receptive skills: A theoretical study. Journal of Language Teaching and Research, 8(5), 996-1005. http://dx.doi.org/10.17507/jltr.0805.22

Depdiknas, (2006). Permendiknas Nomor 22 Tahun 2006 Tentang Standar Isi Sekolah Menengah Atas. Jakarta: Depdiknas.

English, L. D. (Ed.). (2004). Mathematical and analogical reasoning of young learners. Routledge. https://psycnet.apa.org/record/2004-14903-000

Graham, K. J., \& Fennell, F. (2001). Principles and standards for school mathematics and teacher education: Preparing and empowering teachers. School Science and Mathematics, 101(6), 319-327. https://doi.org/10.1111/j.1949-8594.2001.tb17963.x

Gentner, D., \& Smith, L. (2012). Analogical reasoning. Encyclopedia of human behavior, 1, 130-136. https:// doi.org/10.1016/B978-0-12-375000-6.00022-7

Hendrawata, D. (2018). Analisis Analogi Siswa Dalam Menyelesaikan Soal Bangun Datar (Doctoral dissertation, University Of Muhammadiyah Malang).

Hill, H. C., \& Ball, D. L. (2004). Learning mathematics for teaching: Results from California's mathematics professional development institutes. Journal for research in mathematics education, 330-351. https://doi.org/10.2307/30034819

Hasbi, M., Lukito, A., \& Sulaiman, R. (2019). Mathematical Connection Middle-School Students 8th in Realistic Mathematics Education. In Journal of Physics: Conference Series (Vol. 1417, No. 1, p. 012047). IOP Publishing. https:// doi.org/\%2010.1088/1742-6596/1417/1/012047/meta

Holyoak, K. J., Gentner, D., \& Kokinov, B. N. (2001). Introduction: The place of analogy in cognition. The analogical mind: Perspectives from cognitive science, 1-19.

Huitt, W., \& Hummel, J. (2003). Piaget's theory of cognitive development. Educational psychology interactive, 3(2), 1-5.

Isoda, M., \& Katagiri, S. (2012). Mathematical thinking: How to develop it in the classroom (Vol. 1). World Scientific. https://doi.org/10.1142/9789814350853_others03 
Jeannotte, D., \& Kieran, C. (2017). A conceptual model of mathematical reasoning for school mathematics. Educational Studies in Mathematics, 96(1), 1-16. https://doi.org/10.1007/s10649-017-9761$\underline{8}$

Lefa, B. (2014). The Piaget theory of cognitive development: an educational implications. Educational Psychology, 1(9), 1-8.

Lehrer, R., \& Schauble, L. (2000). Developing model-based reasoning in mathematics and science. Journal of Applied Developmental Psychology, 21(1), 39-48. https://doi.org/10.1016/S0193-3973(99)00049-0

National Council of Teachers of Mathematics (NCTM). (2000). Principles And Standards Schools Mathematics. Reston, VA:NCTM.

Norris, P., \& Epstein, S. (2011). An experiential thinking style: Its facets and relations with objective and subjective criterion measures. Journal of personality, 79(5), 1043-1080. https://doi.org/10.1111/j.14676494.2011.00718.x

Richland, L. E., Holyoak, K. J., \& Stigler, J. W. (2004). Analogy use in eighth-grade mathematics classrooms. Cognition and instruction, 22(1), 37-60. https://doi.org/10.1207/s1532690Xci2201_2

Richland, L. E., \& Simms, N. (2015). Analogy, higher order thinking, and education. Wiley Interdisciplinary Reviews: Cognitive Science, 6(2), 177-192. https://doi.org/10.1177/2372732216629795

Richland, L. E., \& Begolli, K. N. (2016). Analogy and higher order thinking: Learning mathematics as an example. Policy Insights from the Behavioral and Brain Sciences, 3(2), 160-168. https://doi.org/10.1177/2372732216629795

Sadiq, R., Kleiner, Y., \& Rajani, B. (2007). Water quality failures in distribution networks - risk analysis using fuzzy logic and evidential reasoning. Risk Analysis: An International Journal, 27(5), 1381-1394. https://doi.org/10.1111/j.1539-6924.2007.00972.x

Sagiv, L., Arieli, S., Goldenberg, J., \& Goldschmidt, A. (2010). Structure and freedom in creativity: The interplay between externally imposed structure and personal cognitive style. Journal of Organizational Behavior, 31(8), 1086-1110. https:// doi.org/10.1002/job.664

Scott, S. G., \& Bruce, R. A. (1995). Decision-making style: The development and assessment of a new measure. Educational and psychological measurement, 55(5), 818-831. https://doi.org/10.1177/0013164495055005017

Shadiq, F. (2007). Penalaran atau Reasoning. Perlu Dipelajari Para Siswa di Sekolah. Jurnal Online. https:/ / fadjarp3g. files. wordpress. com/2007/09/ok-penalaran_gerbang_. pdf.

Smith, E. R., \& DeCoster, J. (2000). Dual-process models in social and cognitive psychology: Conceptual integration and links to underlying memory systems. Personality and social psychology review, 4(2), 108131. https://doi.org/10.1207/S15327957PSPR0402_01

Sternberg, R. J. (Ed.). (1999). Handbook of creativity. Cambridge University Press.

Sternberg, R. J., \& Williams, W. M. (2009). Educational Psychology. 2nd Edition. In by Routledge New York, (ebk) by Amazon (Vol. 24). https://doi.org/10.7202/1016404ar

Vahrum, F. N., \& Rahaju, E. B. (2016). Proses Berpikir Siswa SMP dalam Memecahkan Masalah Matematika Kontekstual Pada Materi Himpunan Berdasarkan Gaya Kognitif Reflective da Reflective. Jurnal Ilmiah Pendidikan Matematika, 3(5), 147-155.

Van de Walle, A., Tiwary, P., De Jong, M., Olmsted, D. L., Asta, M., Dick, A., ... \& Liu, Z. K. (2013). Efficient stochastic generation of special quasirandom structures. Calphad, 42, 13-18. https://doi.org/10.1016/j.calphad.2013.06.006 